\title{
Effect of Heat Treatment and Sulfuric Acid Anodization on Corrosion Resistance of Aluminum Alloy (AA7075)
}

\author{
M. Abdullahi ${ }^{a, *}$ L. S. Kuburi ${ }^{b}$, P. T. Zubairu ${ }^{\text {a }}$, U. Jabo ${ }^{\text {c }}$, A. A. Yahaya ${ }^{\text {d }}$, Y. \\ James $^{\text {a }}$ \\ ${ }^{a}$ Mechanical Engineering Department, Federal Polytechnic, Bida, Niger State, NIGERIA. \\ ${ }^{b}$ Mechanical Engineering Department, Ahmadu Bello University, Zaria, Kaduna State, NIGERIA. \\ ${ }^{c}$ Estate and Municipal Services Department, Usman Danfodio University, Sokoto State, NIGERIA. \\ ${ }^{d}$ Department of Mechanical Engineering, Federal Polytechnic, Bida, Niger State, NIGERIA.
}

\begin{abstract}
This paper, studied the effect of heat treatment and anodization on corrosion resistance of aluminum alloy 7075 (AA7075), with a view to improving its corrosion resistance. Microstructure and micro hardness of the anodic film of the samples were studied with the aid of optical metallurgical microscope and automated micro hardness testing machine. Linear polarization methods were used to assess the corrosion behaviour of the alloy in 0.5M HCl. The microstructure of the annealed sample showed formation of dendrites while precipitation hardened samples in palm kernel oil and SAE 40 engine oil showed precipitates of $M g Z n_{2}$. The SEMS result showed pores and micro cracks on the surfaces of the anodized samples, with the as cast and anodized sample in sulfuric acid exhibiting most compact with few pores. The as cast and sulfuric acid anodized sample shows highest micro hardness value of $205.33 \mathrm{HV}$, while the least value of $150.67 \mathrm{HV}$ was recorded in sample precipitation hardened in SAE 40 engine oil and anodized in sulfuric acid. Analysis of the potentiodynamic polarization data and curves showed a linear relationship (decrease in icorr, decreases the corrosion rate) between current density and the corrosion rate in all the samples. Higher polarization resistance of $15.093 \Omega / \mathrm{cm}_{2}$ was recorded by the as cast and Sulfuric acid (SA) anodized sample while the precipitation treated in SAE 40 engine oil plus SA anodized sample recorded lowest polarization resistance of $5.2311 \Omega / \mathrm{cm}_{2}$. Heat treatment alone improves corrosion resistance of AA 7075 in $0.5 \mathrm{M} \mathrm{HCl}$ solution but heat treatment plus SA anodization does not improve corrosion resistance in the same environment.
\end{abstract}

Keywords: heat treatment, anodization, micro hardness, corrosion, AA7075

\section{INTRODUCTION}

Metals constitutes eighty percent of element in the periodic table and react with oxygen to form basic oxides, it is significant among other engineering materials such as composite, polymer and plastic due to their physical, mechanical and chemical properties, suitable for wide range of applications. Aluminum is the second most widely used metal, highly valuable due to its unique combination of properties such as low density (approximately $2.7 \mathrm{~kg} / \mathrm{cm}^{3}$ ), high ductility, and improve mechanical strength achieved by suitable alloying and heat treatments $[1,2]$.

${ }^{*}$ Corresponding author (Tel: +234 (0)803 504 4103)

Email addresses:

abdullahi.mohammed@fedpolybida.edu.ng (M.

Abdullahi), kuburi6@yahoo.com (L. S. Kuburi),

nmapee@gmail.com (P. T. Zubairu),

uabubakarjabo@gmail.com (U. Jabo),

adamuyahaya370@gmail.com (A. A. Yahaya),

jamesyisa2014@gmail.com (Y. James)
Aluminum is broadly used in the automotive, air-space, building, and electronics industries and environmentally beneficial due to weight reduction [1]. However, when exposes to the atmosphere, its readily oxidized to produce a thin and fragile oxide layer which tends to protect the metallic surface $\left(\mathrm{Al}_{2} \mathrm{O}_{3}\right)$ and prevent further oxidation process.

Historically, steels and alloy have been predominantly used in building and automobile industries since 1920's. Recently, aluminum alloy has been decently used in engineering structural applications owing to its wide range of characteristics such as light weight, non-rusting properties, reasonably good strength and easy fabrication, modern metallurgical control of structure and properties [3].

Although, metals are very important engineering materials, but the serious setback to their mechanical properties is corrosion. The effect of unchecked corrosion therefore is not limited to the state of corroding utility itself but also influences 
economic, health, safety, technological, and cultural consequences to our society $[4,5]$. The basic cause of corrosion is the instability of metals in their refined forms. The metals tend to revert to their natural states through the processes of corrosion. One of the most important factors influencing corrosion is the difference in electrical potential of dissimilar metals when coupled together and immersed in an electrolyte. This potential is due to the chemical natures of the anodic and cathodic regions.

In addition, agitation acts to increase the corrosion rate by bringing fresh corroding solution into contact with the metal. Also, differences in potential from point to point on a single metal surface cause corrosion known as local action and may be due to impurities on the surface or differences in the surface structure or environment. Other factors such as the presence of other ions in solution, the temperature of the solution and the existence of stray electric current- may materially affect corrosion rate $[6,7]$. As is true of the various forms of corrosion, there are many different methods of corrosion prevention and control.

A proven chemical surface engineering technology to increase corrosion and wear resistance is anodizing. This is a chemical surface engineering technique that oxidizes and converts the surface of aluminum to a uniform and continuous alumina oxide film [8]. Alumina has a relatively high hardness $\left(2.9-5.9 \mathrm{~kg} / \mathrm{mm}^{2}\right)$ and is chemically inert [9-12].

Anodization changes the microscopic texture of the surface and changes the crystal structure of the metal near the surface. Anodic films are generally much stronger and more adherent than most types of paint and metal plating, but also more brittle. This makes them less likely to crack and peel from aging and wear, but more susceptible to cracking from thermal stress.

The amount of $\mathrm{Al}_{2} \mathrm{O}_{3}$ formed during anodization is directly proportional to the current density and time while the growth of the film depends on the chemical composition. Concentration of the anodizing electrolytes has little or no solvent action on the oxide coating so that very thinning films usually known as barrier layer type coating are formed, the thickness of which is solely dependent on applied voltage. These types of coatings are typically produced in solutions of borate, boric acid or titrate. Sulfuric acid is an example of electrolytes that has solvent action on the formed coating. Porous film is also formed as the oxidation process continues leading to the formation of relatively thick film $[6,13]$. The aim of this work is to investigate the effect of heat treatment and sulfuric acid anodization on corrosion behavior of aluminum alloy 7075 (AA 7075) with a view to improving its corrosion resistance for engineering applications.

\section{MATERIALS AND METHODS}

\subsection{Materials}

The aluminum alloy 7075 was cast using stir casting method and the result of the elemental composition is presented in Table 1.

The corrosive medium used is $0.5 \mathrm{M} \mathrm{HCl}$ solution. Other materials include commercial aluminum scrap $(260 \mathrm{~g})$ and copper cut-out (8 g) sourced from NOCACO Aluminum company Kaduna, Zinc scrap (16 g), Magnesium scrap (5 g), abrasive emery grinding paper, ACS Reagent Grade Ethanol, distilled water, Analytical reagent grade Sulfuric acid $\left(\mathrm{H}_{2} \mathrm{SO}_{4}\right)$ solution (95\% concentration, $1.83 \mathrm{~g} / \mathrm{ml}$ ), Analytical Reagent grade (90\% concentration, $1.48 \mathrm{~g} / \mathrm{ml})$ Nitric acid $\left(\mathrm{HNO}_{3}\right)$ solution, Laboratory Reagent grade, $\geq 98 \%$ Sodium hydroxide $(\mathrm{NaOH})$, Analytical Reagent grade, $\geq$ $37 \%$ Hydrochloric acid $(\mathrm{HCl})$ solution, Laboratory Reagent grade, $99.99 \%$ Chromium trioxide $\left(\mathrm{Cr}_{3} \mathrm{O}\right)$ crystals, SAE $20 \mathrm{~W} / 50$ engine oil (AMMASCO), Freshly extracted Palm Kernel oil (4 liters) from Edati in Niger State.

\subsection{Equipment}

Equipment used for this research work include: Electric furnace for heating: Brand/make/model: search Tech instruments, 5X-5-12 BoxResistances No. 2392, Charcoal fired crucible furnace, Energy Dispersive X-ray Fluorescence (EDXRF) machine, model: Minpal 4 No. DY 1055, Photographic Visual Metallurgical microscope: Model No. NJF-120A, Scanning Electron Microscope (SEM): Model No. EVO MA- 10, manufacture by Carl, Automated micro hardness tester: Model MV1-PC, Identification No Mh-vA with Max/Min Limit of 220/80 HV, Load 0.3 kgf and Machine No 07/2012-1329, Potentiostat/Galvanostat type PGSTAT 204, serial no. AUT50280 made in Netherlands $75 \mathrm{~W} / 60 \mathrm{~Hz}$, Lathe machine, 12-volt Battery (Delkor): NS 60 LSMF, AMP. HR (20 HR)- 45, RESERVE CAPACITY (MIN)- 75,12V $45 \mathrm{Ah}, \mathrm{N}$ 45, $2 \mathrm{~mm}$ diameter electric wires, Digital Multimeter Model 57030: DC voltage range: $200 \mathrm{mV}-600 \mathrm{~V}$, DC current range: $200 \mu \mathrm{A}-10 \mathrm{~A}, \mathrm{AC}$ voltage range: $200 \mathrm{~V}-$ $600 \mathrm{~V}$, Resistance range: $200 \Omega-2 \mathrm{M} \Omega$, Digital laboratory $\mathrm{pH}$ meter (Range: -2.000 to 20.000 $\mathrm{pH}$, accuracy of \pm 0.002 ), Thermometer (Mercury/ Red spirit filled), Range: -10 to $110{ }^{\circ} \mathrm{C}$, Sensitive laboratory electric weighing balance Model No. FA2004, Rating load: 200 g, Actual scale dividing values: $0.1 \mathrm{mg}$, Accuracy: $200 \mathrm{~g}, 0.1 \mathrm{mg}$, Voltage: 220 v/50 hz, 2-liter capacity Pyrex beaker, Plastic container, Desiccator.

Table 1: Chemical Composition of Cast AA 7075.

\begin{tabular}{lc}
\hline Element & Composition wt.\% \\
\hline $\mathrm{Zn}$ & 5.561 \\
$\mathrm{Mg}$ & 1.049 \\
$\mathrm{Cu}$ & 1.06 \\
$\mathrm{Fe}$ & 1.1 \\
$\mathrm{Ca}$ & 0.02 \\
$\mathrm{Ni}$ & 0.0091 \\
Others each & 0.0009 \\
$\mathrm{Al}$ & 91.2 \\
\hline
\end{tabular}




\subsection{Methods}

The cast rods were machined to $14 \mathrm{~mm}$ diameter and $10 \mathrm{~mm}$ in length (cylindrical in shape). The cylindrical samples were made smooth by thoroughly grinding on emery abrasive grinding papers. Some of the prepared samples were then subjected to aging by heating in a Box-Resistance Furnace Model No 2392 to solutionized at $510^{\circ} \mathrm{C}$ $\pm 5^{\circ} \mathrm{C}$, soaked for 3 hours and then 9 samples were quickly removed and plunged into separate containers containing different quenching media (palm kernel oil and SAE 40 engine oil) at ambient temperatures as specified in [14]. Thereafter, the quenched samples were aged at a temperature of $170^{\circ} \mathrm{C} \pm 5^{\circ} \mathrm{Cas}$ prescribed in [14] standards and then allowed to cool in air.

\subsection{Condition for Anodization}

Prior to anodization, samples were subjected to alkaline cleaning in $5 \% \mathrm{NaOH}$ solution for 5 minutes followed by desmutting in $25 \% \mathrm{HNO}_{3}$ for 2 minutes, washed, rinsed, dried and weighed. Cleaned and weighed (W1) AA 7075 samples were then anodized in solution of $200 \mathrm{~g} / 1 \mathrm{H}_{2} \mathrm{SO}_{4}$ solution at $12 \mathrm{~V}$ for 30 minutes at $30^{\circ} \mathrm{C}$ [5].

\subsection{Experimental Setup for Anodization}

The anodizing facility permitted the control of the anodizing parameters such as current, voltage and temperature. The anodizing setup consisted of a transparent plastic container. A 2-litre capacity Pyrex beaker was placed inside a larger transparent plastic container and the space between them was filed with water. The water contained in the transparent plastic container bath increased the cooling effectiveness and acted as a buffer to maintain constant anodizing solution temperature. A mechanical stirrer was used to stir the anodizing solution and ensure a uniform electrolyte temperature throughout. This was effective to dissipate quickly the heat evolved at the specimen electrolyte interface during anodizing.

Both anode (AA 7075) and cathode (stainless steel $0.50 \mathrm{~mm}$ thick with dimension of $120 \mathrm{~mm}$ length by $110 \mathrm{~mm}$ breath) were connected with electric wires and partially dipped into the acid electrolyte solution (Sulfuric acid), which act as a medium for transporting the ionic species. Both anode and cathode were then connected to the positive and negative terminals of a $12 \mathrm{~V}$ battery which act as a D.C power supply. A multimeter was connected in series with the electrode to measure the current and voltage passing through [15]. When the voltage was applied (for 30 minutes) between the anode and cathode, pores were nucleated and started to grow on the aluminum 7075 alloy surface.

\subsection{Determination of coating thickness}

After anodization, specimen with the anodic coating film were weighed $\left(\mathrm{W}_{2}\right)$ and then subjected to stripping in a solution containing $20 \mathrm{~g} / \mathrm{l}$ of chromium trioxide and $35 \mathrm{ml} / \mathrm{l}$ of phosphoric acid, for 30 minutes at $100^{\circ} \mathrm{C}$, rinsed, dried and weighed $\left(\mathrm{W}_{2}\right)$. From these weights the coating ratio were calculated as follow:

Coating ratio,

$$
C_{R}=\frac{W_{2}-W_{3}}{W_{1}-W_{3}}
$$

Where $W_{2}-W_{3}$ is weight of the anodic oxide coating and $W_{1}-W_{3}$ is the total weight of $\mathrm{Al} 7075$ reacting.

The thickness of the anodic coating was calculated from the weight of anodic coating, surface area and density of the anodic film as follows:

$$
T=\frac{W_{1}-W_{3} \times 10^{4}}{A x \rho}
$$

Where $\mathrm{A}$ is the surface area of the specimen $\left(\mathrm{cm}^{2}\right)$

$$
A=2 \Pi R h+2 \Pi\left(R_{2}-r_{2}\right)+2 \Pi r h
$$

$\rho$ is the density $\left(\mathrm{g} / \mathrm{cm}^{3}\right)$ which is about $2.6 \mathrm{~g} / \mathrm{cm}^{3}$, $T$ is the coating thickness of anodic film $(\mu \mathrm{m}), R$ is the radius of the coupon sample, $r$ is the radius of the drilled hole on the coupon sample and $h$ is the height of the specimen. This is in accordance with the method of [16].

\subsection{Determination of Micro Hardness of the Anodic Film}

The Vicker micro hardness test was performed according to [17] by applying the loads of $10 \mathrm{gf}, 25$ gf and 40 gf at 15 gf interval during 10 seconds.

\subsection{Potentiodynamic Polarization Analysis}

The corrosion behavior of the anodized samples formed in various anodizing conditions were evaluated through Potentiodynamic polarization method in which corrosion parameters such as corrosion potential (ECorr), Corrosion current (ICorr), Polarization resistance (Rp) and corrosion rate (CR) for the AA 7075 samples after their immersion in hydrochloric acid $(\mathrm{HCl})$ test solution for 30 minutes. A potentiostat was coupled to a computer, a glass corrosion kit with graphite rods as counter electrode and a saturated $\mathrm{Ag} / \mathrm{Ag} 3 \mathrm{M}$ $\mathrm{Kcl}$ electrode was also used as the reference electrode (SCE). The $14 \mathrm{~mm} \times 10 \mathrm{~mm}$ test samples (working electrodes) were tightly mounted and positioned at the glass corrosion cell kit leaving the average of $0.8262 \mathrm{~cm}^{2}$ surface in contact with the electrolyte. The process was carried out by applying current density of $40 \mathrm{~A} / \mathrm{cm}^{2}$, scan rate of 0.001 , start and end potential of -1.500 and 1.500 respectively. Polarization curves were plotted using Auto lab data acquisition system, both the corrosion rate and potential were estimated by Tafel extrapolation method using both the anodic and cathodic branches of polarization curves according to $[18,19]$.

\section{RESULTS AND DISCUSSION}

\subsection{Microstructure Analysis}

The micrograph of the as cast, heat treated and anodized AA7075 specimen viewed under metallurgical microscope and the scanning electron microscope (SEM) are presented in Fig. 1a -1d and Fig. $2 \mathrm{a}-2 \mathrm{~d}$ respectively. 


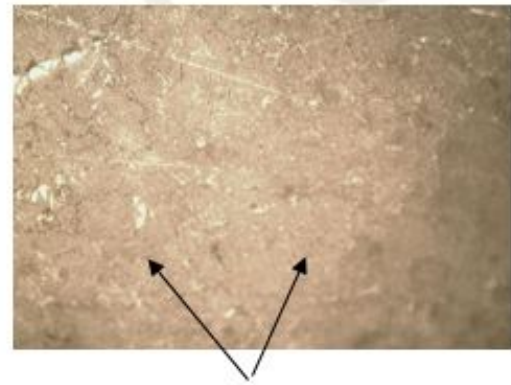

Micro segregation of $\mathrm{MgZn}_{2}$ phase

(a) cast

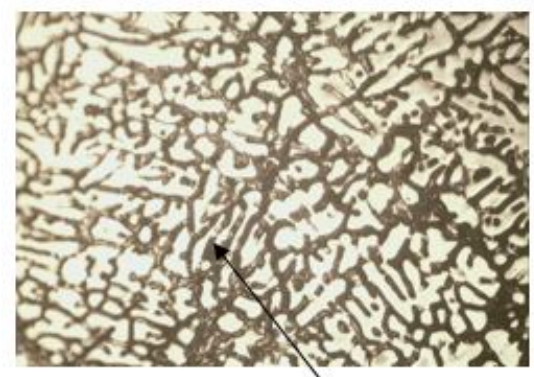

Dendritic networks

(b) annealed

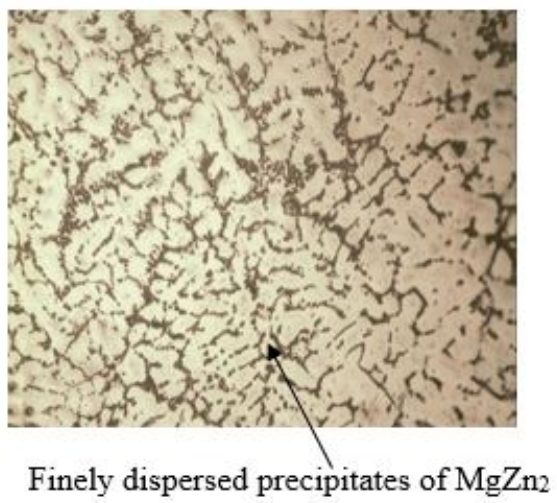

(c) Precipitation Treated in palm kernel oil

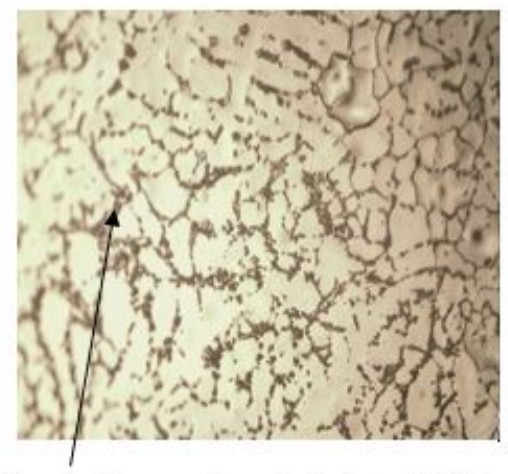

Finely dispersed precipitates of $\mathrm{MgZn} 2$

(d) Precipitation hardened in SAE 40 engine oil

Figure 1: Optical micrograph of AA 7075, showing $\alpha$-Al (white) and intermetallic phase (black). Mag X100: (a) as cast, (b) annealed, (c) Precipitation Treated in palm kernel oil, (d) Precipitation hardened in SAE 40 engine oil.

\section{DISCUSSION}

\subsection{Chemical Composition Analysis}

The chemical composition analysis of the cast AA 7075 was carried out using x-ray fluorescence (XRF) analysis. The result presented in Table 1 shows slight difference in compositions of some elements as quoted in [20]. These differences may be due to impurities and variation in melting temperatures of the charged materials.

\subsection{Effect of Heat Treatment on Microstruc- ture}

The micrographs of AA 7075 specimen are presented in Fig. 1a - 1d, for as-cast, annealed and precipitation hardened conditions. The microstructure of this type of alloys is generally said to be characterized by $\eta$ precipitates (nominally $\left.\mathrm{MgZn}_{2}\right)[21,22]$ as can be observed in Fig. 2a - 2d. The microstructure of the as cast sample (Plate 1a) shows micro segregation of $\mathrm{MgZn}_{2}$ in aluminum matrix which corresponds with the result of [23]. From the micrographs, it can be seen that the microstructures of the precipitation treated alloys (Fig. 1c and 1d) have finer grains and consequently more grain boundaries than the as-cast and annealed alloys. This is based on the fact that there is an increase in the volume of the precipitated intermetallic compounds during precipitation hardening process and also refinement of the precipitated constituent particles [24]. The grains of the palm kernel oil quenched sample are finer when compared with the grains of SAE 40 engine oil quenched sample, this is due to slower cooling rate of the palm kernel oil. The presence of dispersed precipitate of $\mathrm{MgZn}_{2}$ correspond with the result of [25-27] who discovered that aging heat treatment of $\mathrm{Al}-\mathrm{Zn}-\mathrm{Mg}-\mathrm{Cu}$ alloy lead to the formation $\mathrm{MgZn}_{2}$ intermetallic phase in the structure. In their study on Investigation of the Quenching Properties of Selected Media on 6061 Aluminum Alloy, [28] reported that increase solution treatment temperature was found in improved soluble precipitates in the alloy, and the heat extraction capacity of the quenching medium also contributed to the formation of fine precipitates. The elimination of micro segregations after annealing and precipitation treatment operations in the present investigation is in agreement with the findings of [29].

\subsection{Effect of Heat Treatment on the Anodic Film Formation}

In this study, the effect of surface microstructure resulting from different heat treatment processes on the progress of anodic film on AA 7075 was analyzed. Figures $2 \mathrm{a}-2 \mathrm{c}$ showed the SEM micrographs of the surface morphologies of sulfuric acid (SA) anodized AA 7075 (subjected to different heat treatment processes). The surface of the as cast sample exhibited the most compact layer with fewer surface pores [30]. Micro cracks were seen on the surface of the SA anodized specimen. These micro cracks on the surfaces of the anodized layers may likely be caused by internal 


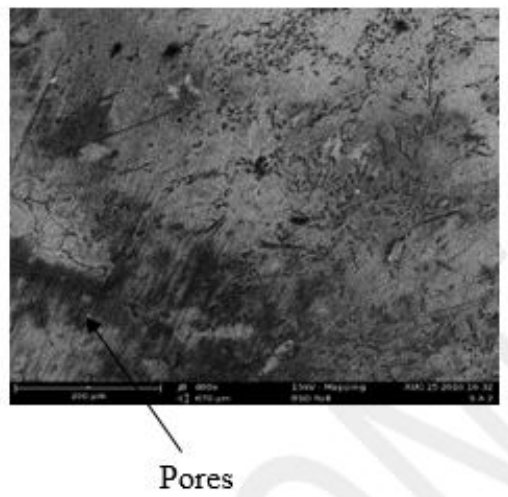

(a)

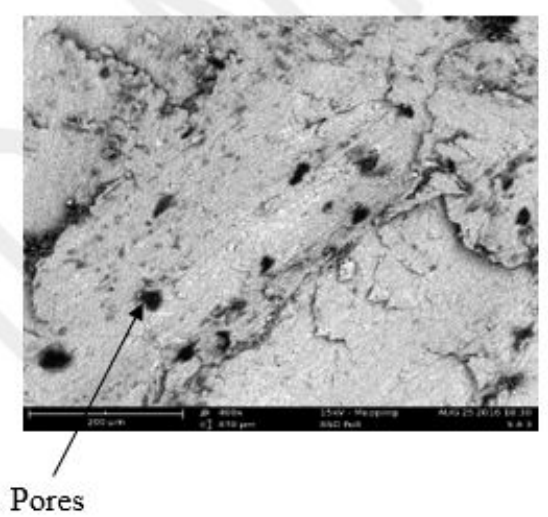

(b)

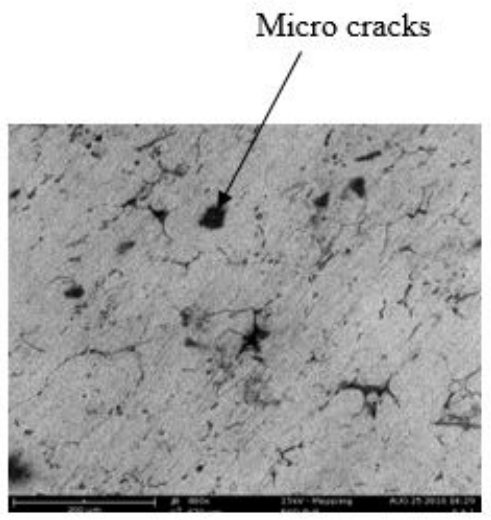

(c)

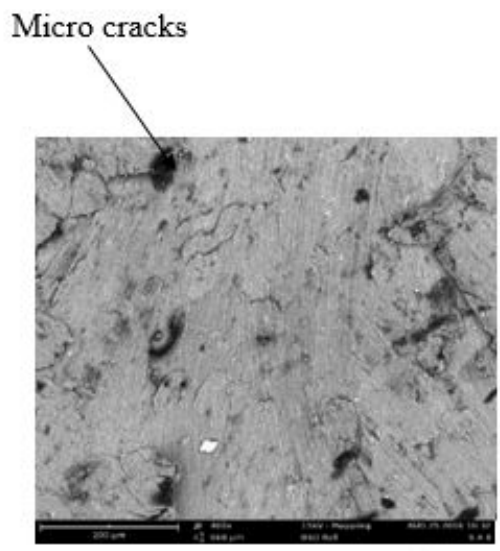

(d)

Figure 2: SEM micrograph of as cast + SA anodized (a), Annealed + SA anodized sample (b), Precipitation treated sample in palm kernel oil + SA anodized (c) and Precipitation treated sample in SAE 40 engine oil + SA anodized sample (d). stress generated by the growth of the oxide at the substrate/oxide interface [31]. This result is in agreement with the observation of [32].

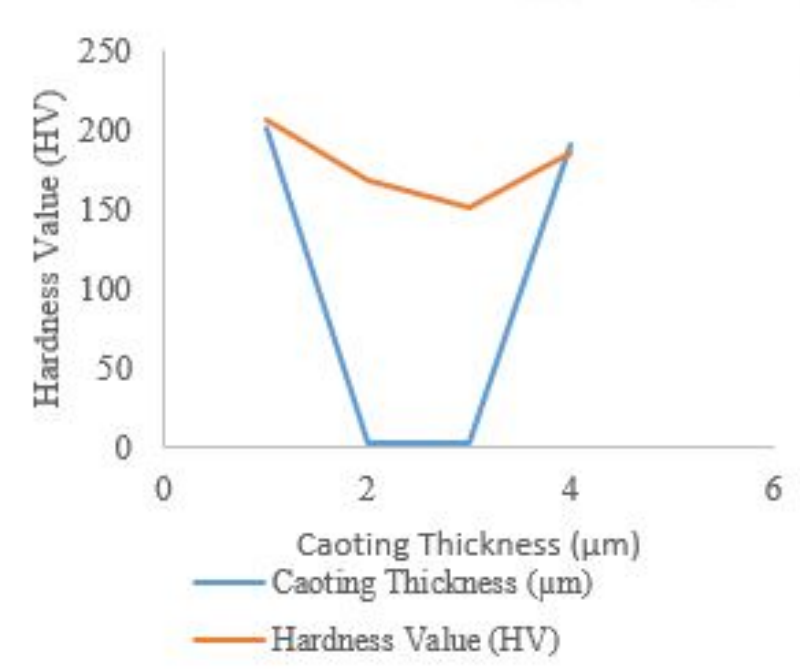

Figure 3: Variation of micro hardness and coating thickness of the anodic film formed on the heat treated and sulfuric acid anodized AA 7075 samples.

\subsubsection{Micro hardness and coating thickness of the anodic film}

Figure 3 shows variation of hardness value with the coating thickness of the anodic film formed on the as cast, heat treated and heated and anodized samples in sulfuric acid (SA). Decrease in hardness with increase in coating thickness was observed. Highest micro hardness value was recorded at $186 \mathrm{HV}$ for annealed plus SA anodized sample. At very high coating thickness (248.38 $\mu \mathrm{m})$, the micro hardness is maximum and hence the rate of formation of coating is more. The difference in weight gain between various coatings correlates their surface morphology [33]. This result is in agreement with the result put forward by [34].

\subsection{Effect of Heat Treatment and Anodiza- tion on the Corrosion Resistance}

Figure 4 show Potentiodynamic polarization curves of the heat treated and anodized AA 7075 samples exposed to $0.5 \mathrm{M} \mathrm{HCl}$ solution. The corrosion rate of all the samples studied showed prolong active region (anodic).

Observations from the results indicated that the corrosion rates are very similar in trend for all the examined samples irrespective of the treatment. This is because the samples were from the same alloy which was cast and solidified in similar conditions of cooling rate. The corrosion current densities (jcorr) were obtained from polarization curves in Fig. 4 by Tafel plots using both cathodic and anodic branches of the polarization curves. The corrosive environment demonstrated a decreased in corrosion rate and current density while the heat treatment processes increases $-\mathrm{E}$ (V) and $R_{P}\left(\Omega \mathrm{cm}^{2}\right)$ of the samples. This result agrees with the result of $[35,36]$. The heat treated 


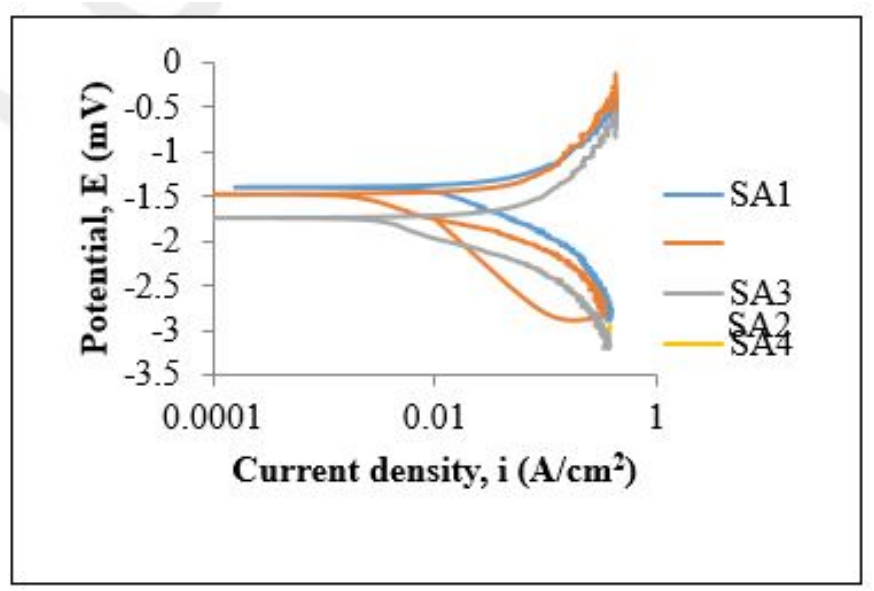

Figure 4: Potentiodynamic polarization curves of heat treated and sulfuric acid anodized AA7075 samples exposed to $0.5 \mathrm{M} \mathrm{HCl}$ solution.

AA 7075 samples in test environment showed that corrosion rate decreases from $32.388 \mathrm{~mm} / \mathrm{yr}$ to $4.8893 \mathrm{~mm} / \mathrm{yr}$ for sample annealed sample plus sulfuric acid (SA) anodization to SAE 40 engine oil precipitation treated plus SA anodization respectively.

Highest potential $(-1976 \mathrm{mV})$ was observed for the as cast plus sulfuric acid anodized sample while the highest polarization resistance (15.093 $\Omega / \mathrm{cm}^{2}$ ) was observed for the as cast plus SA anodized sample. This result is in agreement with the result of [37].

Lowest polarization resistance $\left(5.2311 \Omega / \mathrm{cm}^{2}\right)$ was recorded by the sample precipitation treated in SAE 40 engine oil plus SA anodized sample as can be seen in Fig. 5 .

Samples subjected to heat treatment and SA anodization recorded lower corrosion resistance when compared with the samples subjected to heat treatment alone (as can be seen in Fig. 5), which suggest that heat treatment plus SA anodization does not improve the corrosion resistance of AA 7075. Higher polarization resistance (15.093 $\Omega \mathrm{cm}^{2}$ ) recorded by the sample as cast and SA anodized which may be attributed to few pores on its surface as can be seen in Fig. 2a. It was found that the anodizing potential is critical in determining the anticorrosion performance; lower potential generates finer pores that provide enhanced corrosion protection compared with the larger pores generated at higher potentials [38].

\section{CONCLUSIONS}

The results obtained from this research indicates significant role of heat treatment, heat treatment and anodization on the corrosion behavior of AA 7075. The corrosive medium did not penetrate the anodic film uniformly but preferentially at local sites, resulting in localized corrosion of the anodized alloy. Based on the results presented, the following conclusions are made:

1. The chemical composition analysis of AA 7075 that was carried out (Table 1 ) shows the pres-

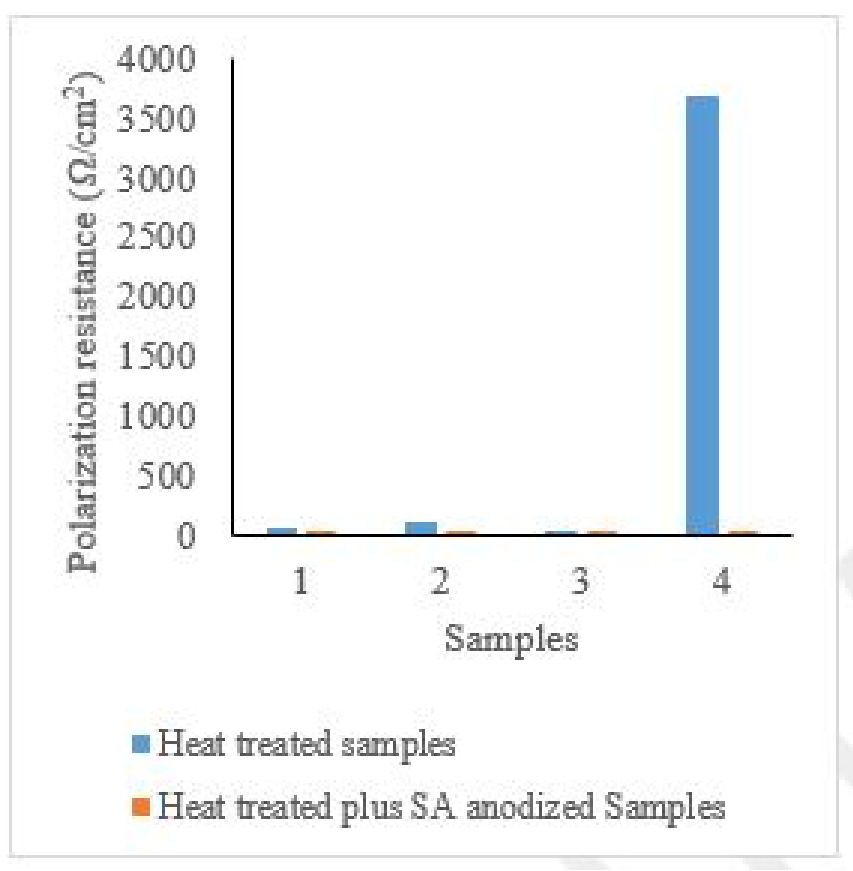

Figure 5: Variation of the effect of heat treatment on polarization resistances of AA 7075 before and after anodization in sulfuric acid.

ence of $91.2 \% \mathrm{Al}, 5.561 \% \mathrm{Zn}, 1.049 \% \mathrm{Mg}$, $1.06 \% \mathrm{Cu}, 1.10 \% \mathrm{Fe}, 0.02 \% \mathrm{Ca}$ and $0.0091 \%$ $\mathrm{Ni}$, and $0.0009 \%$ other each with slight difference in the compositions of some elements quoted in [20].

2. Heat treatment leads to the formation of $\mathrm{MgZn}_{2}$ phase on AA 7075. Annealed sample gives rise to non-uniformly distributed and dissolved coarse grains of $\mathrm{MgZn}_{2}$ phase. However, the precipitation treatment in palm kernel oil and SAE 40 engine oil samples showed finely dispersed precipitates of $\mathrm{MgZn}_{2}$ in the aluminum matrix. The as cast sample shows $\mathrm{Zn}-\mathrm{Al}-\mathrm{Cu}$ intermetallic phases.

3. The annealing plus SA anodization only improves the coating thickness of anodic film formed on AA 7075. Also, the as cast plus anodized in SA samples appeared to have better micro hardness; this suggest that heat treatment does not improve coating thickness and micro hardness of AA 7075.

4. The SEM micrograph of the samples shows pores and micro cracks irrespective of the heat treatment the samples were subjected to.

5. Compared with the as cast, we can say that heat treatment alone improves polarization resistance of AA 7075 in $0.5 \mathrm{M}$ HCl solution but heat treated plus SA anodization does not improve polarization resistance in the same environment. 


\section{Acknowledgement}

The authors are very much thankful to the management of Ahmadu Bello University Zaria and Federal Polytechnic Bida, for providing research facilities.

\section{References}

[1] S. Chiu, "Surface modificaion Processes and Fracture Behavior of 7075-T6 Aerospace Al-Alloy," Ph.D. dissertation, Tatung University, China, 2004

[2] P. Sheasby and R. Pinner, The Surface Treatment and Finishing of Aluminum and its Alloys 2, 6th ed. ASM International and Finishing Publications, 2001.

[3] R. B. Ramle, "Corrosion rate of aluminum alloy by anodizing with emphasis on body panel application," 2009, b.Sc Thesis.

[4] Corrosion Engineering. New York: Mc Graw Hill books Coy, 1967.

[5] L. Kuburi, I. Malik, A. Alabi, and M. Dauda, "Effect of corrosion on the microstructure of anodized aluminum," International Journal of Applied Engineering Research, vol. 7, no. 11, 2012.

[6] P. Madakson, I. Malik, S. Laminu, and I. Bashir, "Effect of Anodization on the corrosion behavior of Aluminium Alloy in $\mathrm{HCl}$ acid and $\mathrm{NaOH}$," International Journal of Materials Engineering, vol. 2, no. 4, pp. 38-42, 2012.

[7] H. Uhlig, Corrosion and corrosion control. London: John Wiley and sons, 1962.

[8] L. Velterop, "Phosphoric sulphuric acid anodising: An alternative for chromic acid anodising in aerospace applications," ATB Metallurgie, vol. 43, no. 1--2, pp. 284$-289,2003$.

[9] A. Yerokhin and R. Khan, "Anodising of light alloys," in Surface Engineering of Light Alloys: Aluminium, Magnesium and Titanium Alloys. Cambridge: Woodhead Publishing Ltd., 2010, p. 83.

[10] W. Skoneczny, "Analysis of morphology and microstructure of $\mathrm{Al}_{2} \mathrm{O}_{3}$ layers," Material Science, vol. 46, pp. 276$-281,2010$.

[11] J. Runge and A. Pomis, "Plat. Surf. Finish." 2003.

[12] N. Bartolo, E. Sinagra, and B. Mallia, "Optimising sulfuric acid hard coat anodising for an Al-Mg-Si wrought aluminum alloy," Materials Science-Poland, vol. 32, no. 2, pp. 136-144, 2014.

[13] V. Raghavan, Physical Metallurgy, Principles and Practice, Pretice. India: John Wiley and sons, Hall of India Private Ltd.

[14] A. S. B917/917M, Standard Practice for Heat Treatment of Aluminum-Alloy Casting from All Processes. West Conshohocken, USA: ASTM International, 2008, www.astm.org.

[15] A. S. Alejandro, "Structural engineering of nanoporous anodic alumina and applications," Ph.D. dissertation, Universitat Rovirai Virgili, VIRGILI Tarragona, 2010.

[16] S. Sigamani, P. Thangavelu, K. Srinivasan, and M. Selvan, "Studies of AC Anodizing of Aluminum in Sulfuric Acid Electrolyte Containing Sodium Sulfate," International Journal of Innovative Research in Science, Engineering and Technology, vol. 3, no. 6, pp. 13 869-13 875, 2014.

[17] "Standard test method for knoop and vivkers hardness of materials," 2012.

[18] M. J. Clerk, A Treatise on Electricity and Magnetism, 3rd ed. Oxford: Clarendon, 1892, vol. 2.

[19] I. Jacobs and C. Bean, "Fine particles, thin films and exchange anisotropy," in Magnetism, G. Rado and H. Suhl, Eds., vol. III. New York: Academic, 1963, pp. 271-350.

[20] ASTM B 211- 03, Standard Specification for Aluminum and Aluminum-Alloy Bar, Rod, and Wire. ASTM, 2009.

[21] R. O. Wislei, E. S. Jose, M. A. Celia, M. Freire, and A. G. Cardona, "The role of $\mathrm{Al}_{2} \mathrm{Cu}$ and of dendritic refinement on Surface Corrosion Resistance of Hypoeutectic Al-Cu Alloy Immersed in $\mathrm{H}_{2} \mathrm{SO}_{4}$, Journal of $\mathrm{Al}$ loys and Comp., vol. 44, no. 3, pp. 87-93, 2007.

[22] P. A. Rometsch, Z. Yong, and K. Steven, "Heat treatment of 7xxx series aluminium alloys-Some recent developments," Transactions of Nonferrous Metals Society of China, vol. 24, no. 7, pp. 2003-2017, 2014.
[23] K. H., U. M., C. A., Özyürek D., Caliskan A., and E. R. E., "The effect of aging on the machinability of aa7075 aluminium alloy," Scientific Research and Essays, vol. 7, no. 27, pp. 2424-2430, 2012.

[24] A. Mohammed, "Effects of Ni Additions on the Mechanical Properties and Corrosion Resistance of Al-Cu-Si Alloy," 2014, M.Sc. thesis.

[25] D. I. Adeyemi, A. Bolaji, O. A. Mosobalaje, J. O. Oluyemi, and D. S. Moshood, "Effect of Heat Treatment on some Mechanical Properties of 7075 Aluminum Alloy," Material Research, vol. 16, no. 1, pp. 190-194, 2013.

[26] E. Salamci, "Ageing behavior of spray cast Al-Zn-Mg-Cu alloys." Turk Journal of Engineering and Environmental Science, vol. 25, no. 6, pp. 681-686, 2001.

[27] D. Z. W., Z. M. Sun, B. L. Shao, T. T. Zhou, and C. Q. Chen, "Quantitative evaluation of precipitates in an $\mathrm{Al}-\mathrm{Zn}-\mathrm{Mg}-\mathrm{Cu}$ alloy after isothermal aging," Material Characterization, vol. 56, no. 2, pp. 121-128, 2006. [Online]. Available: http://dx.doi.org/10.1016/j.machar. 2005.10.004

[28] O. K. Abubakre, U. P. Mamaki, and R. A. Muriana "Investigation of the Quenching Properties of Selected Media on 6061 Aluminum Alloy," Journal of Minerals and Materials Characterization and Engineering, vol. 8, no. 4, pp. 303-315, 2009.

[29] K. J. Akiluwade, D. A. Isadare, M. O. Adeoye, A. R. Adetunji, K. M. Oluwasegun, and A. L. Rominiyi, "Effect of As-cast Cooling on the Microstructure and Mechanical Properties of Age-Hardened 7000 Series Aluminum Alloy," International Journal of Materials Engineering, vol. 5, no. 1, pp. 5-9, 2015.

[30] M. Z. Mubarok, S. Wahab, and S. Wahyudi, "Effect of Anodizing Parameters in Tartaric-Sulphuric Acid on Coating Thickness and Corrosion Resistance of Al 2024 T3 Alloy," Journal of Minerals and Materials Characterization and Engineering, vol. 3, no. 1, pp. 154-163, 2015

[31] A. I., T. F. D., D. J., and K. L., "The effect of heat treatment on the structure and abrasive wear resistance of autocatalytic nip and nip-sic coatings," Surface and Coatings Technology, vol. 149 , no. 2-3, pp. 263-278, 2002.

[32] Y. Goueffon, L. Arurault, C. Mabru, C. Tonon, and P. Guigue, "Black anodic coatings for space applications: study of the process parameters, characteristics and mechanical properties," Journal of Materials Processing Technology, vol. 209, no. 11, pp. 5145-5151, 2009.

[33] H. H. Shih and S. L. Tzou. (2001) Surf. coat. technol. 124 (278). [Online]. Available: http://www.surfcoat.com

[34] V. M. Prisley, K. Shajan, and K. G. Sunny, "Study of Process Parameters on the Thickness and Micro Hardness During the Sulfuric Acid Anodization of AA6061," International Journal of Engineering and Innovative Technology, vol. 3, no. 6, pp. 110-114, 2013.

[35] V. R. Capelossi, M. Poelman, R. P. B. Hernandez, H. G. Melo de, and M. G. Oliver. (2014) Corrosion protection of clad aa2024 anodized in sulphuric and tartaric sulphuric acid sealed with sol-gel hybrid coatings. [Online]. Available: http://www.researchgate.net/

[36] A. P. I. Popoola, O. S. I. Fayomi, and M. Abdulwahab, "Degradation Behaviour of Aluminium in $2 \mathrm{M}$ $\mathrm{HCl} / \mathrm{HNO}_{3}$ in the Presence of Arachis hypogeae Natural Oil," International Journal of Electrochemical Science, vol. 7, pp. 5817-5827, 2012.

[37] M. Belkhaouda, L. Bazzi, R. Salghi, O. Jbara, A. Benlhachmi, B. Hammouti, and J. Douglad, "Effect of the heat treatment on the behavior of the corrosion and passivation of 3003 aluminium alloy in synthetic solution," Journal of Material Environmental Science, vol. 1, no. 1, pp. 25-33, 2010.

[38] M. Curioni, P. K. Skeldon, E. G. E. Thompson, and J. Ferguson. (2012) Corrosion behavior of aa 2024 t3 aluminum alloy. [Online]. Available: http//www.jes. ecsdl.org 